throughout the book, and a useful index has been appended. The author is to be congratulated on his success in presenting the results of different investigators as a connected whole, and on having produced a treatise which will be the standard treatise on the subject for a long time.

\section{Mathematics for the Practical Man}

Mathematics for Self-Study Series. By J. E. Thompson. (1) Arithmetic for the Practical Man. Pp. xiii +269 . (2) Algebra for the Practical Man. Pp. xviii +291 . (3) Trigonometry for the Practical Man. Pp. $\mathrm{x}+204$. (4) The Calculus for the Practical Man. Pp. $\mathrm{x}+323$. (London: George Routledge and Sons, Ltd., 1931.) $7 s, 6 d$. net each volume.

(5) Mathematics : a Text-book for Technical Students. By Bevis Brunel Low. Pp. vii +448 . (London, New York and Toronto: Longmans, Green and Co., Ltd., 1931.) 12s. $6 d$. net.

THE science of mathematics, the most funda1 mental of all intellectual activities, has been studied since the dawn of history, and almost certainly before that. The motives which impel this study are various, but it would scarcely be an exaggeration to say that everyone uses mathematics in one form or another. In the past, many of the advances of pure mathematics have been bound up with practical applications. For example, it is probably not often realised that the Gibbs phenomenon of Fourier series was brought into prominence by results obtained in using the harmonic analyser of Michelson and Stratton, and was at first attributed to an inaccuracy in the machine itself.

The fascinating study of pure mathematics for its own sake is an occupation which is of necessity confined to a few who have their own specialised literature available. The corresponding class of students of advanced applied mathematics are also catered for. But beyond these specialists there remain two other larger classes; those who are interested in scientific activities generally, especially such aspects as can be appreciated by a general knowledge of elementary mathematics, and those who regard mathematics as a working tool in their daily pursuits and wish to extend their knowledge for severely practical aims. To treat these as potential specialists in mathematics would be a great mistake, and it is only fair that literature should be available which will meet their needs.

The books listed above are essentially intended for the student who is interested in the meaning and simpler technique of mathematies but has no teacher to help him. They are written in a pleasant and somewhat diffuse style so as to anticipate, so far as possible, the difficulties of those who have to follow a written explanation unaided. A paragraph from the preface of (2) deserves to be quoted, and points a moral which should not be overlooked by teachers of elementary mathematics.

"The book is rigorous in that it is scientific in its approach. It attempts to explain and not to side-step obstacles and difficult points. There can be no non-mathematical book on mathematics, and popularisation may only be gained through clarity of expression and through a human and commonsense approach with a minimum of formality."

An author who expresses this view demands respect, the more so since he has acted upon the principle here stated throughout the four books of the series.

The book on the calculus deserves special notice on account of its novel manner of approach, namely, by the method of rates and not by the method of limits. The idea of limit is of course implicit in that of rate, so that the student starts at a more advanced point than usual, but at a point which appeals to the practical mind and from which it is possible to obtain and employ the simpler results and methods without straining the reader's capability. This book has been written with amazing skill, and forms a fitting conclusion to a series which certainly fulfils the author's aim of catering for those who wish to obtain a practical mastery of some of the more usual and directly useful branches of mathematical science.

The books are well worth reading, they are eminently readable, and, in spite of the impression which might be conveyed by the titles, they do not make the main ideas subservient to practical problems. They have a wealth of fully worked examples and plenty of exercises.

(5) This book is of a rather different character from the foregoing, as it supplies a comprehensive course in analysis of a rather more advanced kind. It is intended for those who wish to make practical use of the subject in engineering, physics, chemistry, and other technical sciences. The author, however, does not call his subject "Practical Mathematics", for, as he justly points out, there is plenty of room for a difference of opinion as to what is practical, The book covers a wide range from simple equations to elementary differential equations. An excellent feature is the plentiful use of diagrams, of which there are 409. There are many well-chosen, worked examples and numerous exercises. The book can be recommended.

L. M. Milne-Thomson. 